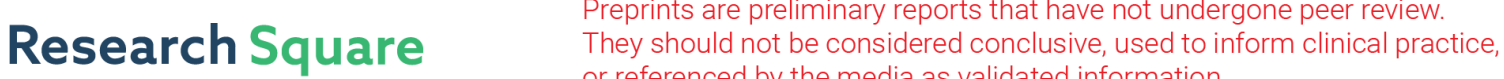 \\ or referenced by the media as validated information. \\ The impact of RMD on urban runoff cannot be ignored in urban hydrologic management
}

Yesen Liu

China Institute of Water Resources and Hydropower Research

yaohuan huang ( $\nabla$ huangyh@igsnrr.ac.cn )

Chinese Academy of Sciences

yuanyuan liu

China Institute of Water Resources and Hydropower Research

\section{Research Article}

Keywords: rainfall movement direction(RMD), rainfall intensity(RI), flood risk

Posted Date: July 15th, 2021

DOI: https://doi.org/10.21203/rs.3.rs-711351/v1

License: (c) (1) This work is licensed under a Creative Commons Attribution 4.0 International License.

Read Full License 


\title{
The impact of RMD on urban runoff cannot be ignored in urban hydrologic management
}

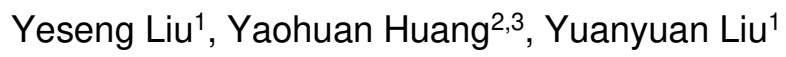 \\ ${ }^{1}$ State Key Laboratory of Simulation and Regulation of Water Cycle in River Basin, China Institute of Water \\ Resources and Hydropower Research, Beijing, China \\ ${ }^{2}$ Institute of Geographic Sciences and Natural Resources Research, Chinese Academy of Sciences, Beijing, \\ China \\ ${ }^{3}$ College of Resource and Environment, University of Chinese Academy of Sciences, Beijing, China \\ Corresponding author: Yaohuan Huang (huangyh@igsnrr.ac.cn)
}

\begin{abstract}
Urban floods have been exacerbated globally, associated with increasing spatial-temporal variations of rainfall. However, compared with rainfall variabilities of intensity and duration, the effect of rainfall movement direction(RMD) is always ignored. Based on 1313 rainfall scenarios with different combinations of rainfall intensity(RI) and RMD in a typical rainy city of Shenzhen in China, we find that the effect of RMD on the peak runoff may reach up to $20 \%$, which will decrease to less than 5\% under heavy RI conditions. In addition, our results show that the impact of RMD is almost symmetrical and is associated with the direction of the river. The closer RMD is to the Linear Directional Mean of upstream, the larger peak runoff of section is. Our results reveal that RMD is significant to urban peak runoff in the downstream reaches, which should be considered in urban hydrological analysis.
\end{abstract}

\section{Introduction}

Extreme rainstorms have been increasing in urban areas due to continued global warming and rapid urbanization ${ }^{1-4}$. This increase is expected to lead to an increment in urban runoff generation and, consequently, to the intensification of urban flood risks ${ }^{5,6}$. During 2010-2018, more than 160 cities in China suffered from floods each year ${ }^{7}$. Hydrological processes in urban areas are sensitive to small-scale temporal and spatial variations in rainfall ${ }^{8}$. Furthermore, the probability of extreme rainfall in urban areas is very likely to increase, with high spatial and temporal variabilities $^{9,10}$, yielding further uncertainties in urban runoff estimations and flood-related damages $^{11,12}$. Understanding the impacts of spatial and temporal rainfall variabilities on runoff is significant for urban hydrologic management (e.g., urban drainage design and construction, forecasting and prevention of flood risk $)^{13-15}$.

However, the interactions among extreme rainfall variability, river features and runoff responses remain poorly understood, especially in urban areas ${ }^{11,16}$. Such attributions require sufficient information about the spatial distribution of short-term rainstorms and runoff responses, which are lack of measurements for the sudden rainfall process and the complex inhomogeneity of urban areas introduced by building envelope. With the development of new instruments, techniques and methods for capturing rainfall and hydrological processes at high resolution, urban hydrological models, such as Storm Water Management Model ${ }^{17}$, have been proposed and applied in urban hydrologic management ${ }^{18,19}$. Although various components of rainfall variability such as the RI, rainfall duration spatial and temporal resolution, degree of 
imperviousness are involved in previous studies, these components are far from completed. For example, similar extreme rainfall patterns of RI and rainfall duration in the same urban area may induce different flood damages. As a result, there remains critical errors and uncertainties in the impacts of rainfall variabilities on hydrological process such as runoff and floods ${ }^{20}$.

RMD is a significant component of rainfall variability ${ }^{21-27}$ that is always ignored. While some studies have found no impact of RMD on hydrological responses ${ }^{8,28}$, relatively few studies reported in the literature have remained inconclusive with respect to the impact of RMD on urban runoff. This contrast may be explained by 1) the limited RMDs observed from rainstorm events, for which is almost fixed rather than 360 degree and lack information in an urban area; 2) isolated analyses of the impacts of RMD were conducted in these studies by neglecting the interactions between RMD and the directions of urban river segments.

In this study, we focus on verifying whether RMDs play a significant role in generating peak runoff in urban areas. This paper is organized as follows: Section 2 briefly introduces the study area and the experimental design. Results are given in section 3 , which also summarizes the main findings of the the impact of RMD on runoff. Methods of hydrological model and rivers feature calculation are presented as supporting information.

\section{Data}

Case study area of Shenzhen city in China. The typical rainy city of Shenzhen in China, with 4 urban rivers, is selected as the study area ${ }^{29}$, this city has complete hydrological infrastructure and observation information systems. Shenzhen, located in the southeast coast of China, is the rapidest urbanization city in China with high urban flood risk caused by extreme rainfall. Shenzhen city ranks fifth among the 136 costal cites in the world in terms of future flood loss risk ${ }^{30}$. Shenzhen city is a typical case study area, in which the spatial and temporal variations of rainfall is wide with rapid movement and obvious "squall line" 31 . What is more, urban hydrological datasets are sufficient in Shenzhen, which is benefit from a 30 million RMB project of building urban flood model began in 2018. These datasets include underground pipe network data (nearly $3000 \mathrm{~km}$ ), 1:1000 terrain data, 13 years of rainfall monitoring data, historical water level data, reservoir operation data, etc.

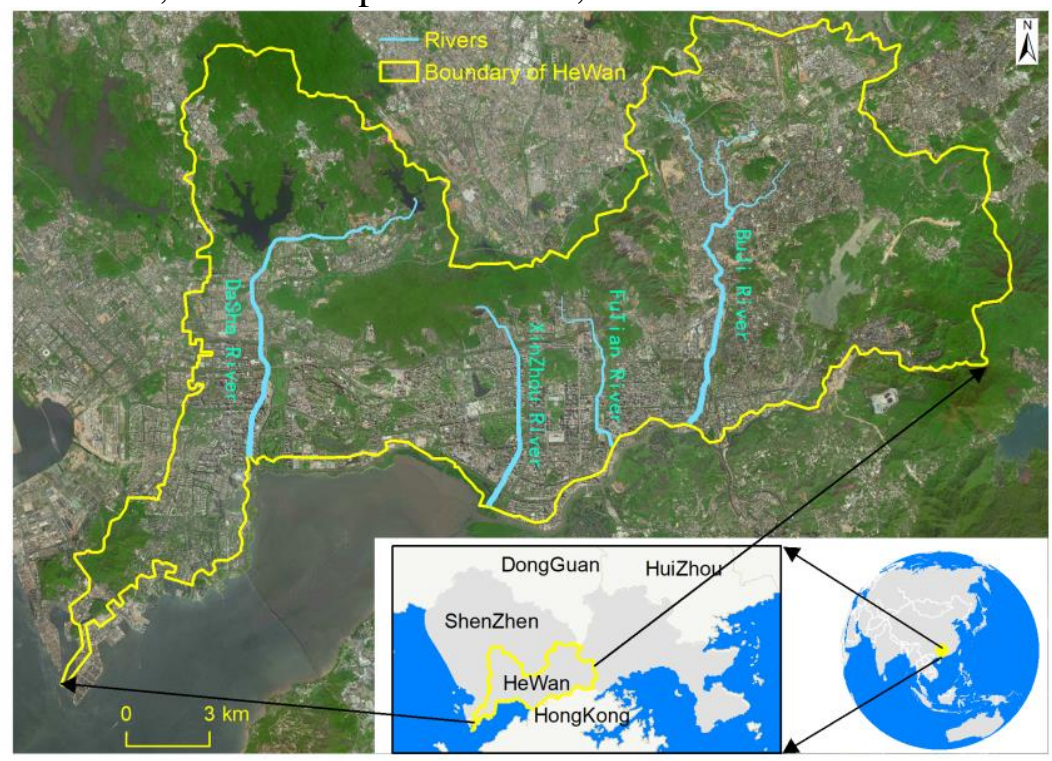

Figure 1. Location of the four rivers 


\section{Methods}

Construction of rainfall schemes.We designed the idealized experimental conditions of RI and RMD to construct comprehensive rainfall schemes. According to the RI value of 132.7 $\mathrm{mm} / \mathrm{h}$ recorded once every 1000 years in Shenzhen, we constructed 13 RIs with $10 \mathrm{~mm}$ intervals from $10 \mathrm{~mm} / \mathrm{h}$ to $130 \mathrm{~mm} / \mathrm{h}$, and chose the commonly used Chicago rain pattern (Tab.1) to represent short-term rainfall. In addition, 100 moving directions with equal intervals were designed to reflect the continuous RMD. The asynchronous rainfall process of the whole basin is set to 3 hours based on the average moving speed of the rainfall center $(10 \mathrm{~km} / \mathrm{h})$ and the diameter of the circumscribed circle of the basin $(30 \mathrm{~km})$. By combining RI and RMD, 1300 rainfall processes $(13 \mathrm{RIs} \times 100 \mathrm{RMDs}=1300)$ were constructed in Fig.2. The two rainfall distribution maps in Fig 2. show distributions when the RI is $80 \mathrm{~mm}$ and the RMDs are 15 and 80 respectively.

\begin{tabular}{|c|c|c|c|c|c|c|c|c|c|c|c|c|c|}
\hline \multirow{2}{*}{ RI scheme } & \multirow[b]{2}{*}{ Total rainfall } & \multicolumn{12}{|c|}{ rainfall of 5 minutes intervals } \\
\hline & & 5 & 10 & 15 & 20 & 25 & 30 & 35 & 40 & 45 & 50 & 55 & 60 \\
\hline RI1: & 10 & 0.4 & 0.6 & 0.8 & 1.4 & 2.0 & 1.2 & 0.9 & 0.7 & 0.6 & 0.5 & 0.5 & 0.4 \\
\hline RI2: & 20 & 0.9 & 1.1 & 1.6 & 2.8 & 4.0 & 2.4 & 1.8 & 1.4 & 1.2 & 1.0 & 0.9 & 0.8 \\
\hline RI3: & 30 & 1.3 & 1.7 & 2.4 & 4.3 & 5.9 & 3.7 & 2.7 & 2.1 & 1.8 & 1.6 & 1.4 & 1.2 \\
\hline RI4: & 40 & 1.8 & 2.3 & 3.2 & 5.7 & 7.9 & 4.9 & 3.6 & 2.9 & 2.4 & 2.1 & 1.8 & 1.7 \\
\hline RI5: & 50 & 2.2 & 2.8 & 4.0 & 7.1 & 9.9 & 6.1 & 4.5 & 3.6 & 3.0 & 2.6 & 2.3 & 2.1 \\
\hline RI6: & 60 & 2.7 & 3.4 & 4.7 & 8.5 & 11.9 & 7.3 & 5.4 & 4.3 & 3.6 & 3.1 & 2.8 & 2.5 \\
\hline RI7: & 70 & 3.2 & 4.0 & 5.5 & 9.6 & 13.2 & 9.3 & 6.2 & 5 & 4.2 & 3.7 & 3.3 & 3.0 \\
\hline RI8: & 80 & 3.9 & 4.7 & 6.3 & 10.7 & 14.6 & 10.3 & 7.1 & 5.8 & 5.0 & 4.4 & 4.0 & 3.6 \\
\hline RI9: & 90 & 4.5 & 5.4 & 7.1 & 11.8 & 16.1 & 11.3 & 7.9 & 6.5 & 5.7 & 5.1 & 4.6 & 4.3 \\
\hline RI10: & 100 & 5.1 & 6.1 & 7.9 & 12.9 & 17.6 & 12.3 & 8.7 & 7.3 & 6.4 & 5.7 & 5.2 & 4.8 \\
\hline RI11: & 110 & 5.8 & 6.7 & 8.6 & 13.9 & 18.8 & 14.1 & 9.5 & 8.0 & 7.0 & 6.3 & 5.9 & 5.5 \\
\hline RI12: & 120 & 6.3 & 7.4 & 9.4 & 15.2 & 20.7 & 15.3 & 10.3 & 8.7 & 7.6 & 7.0 & 6.4 & 6.0 \\
\hline RI13: & 130 & 6.8 & 8.0 & 10.2 & 16.4 & 22.4 & 16.4 & 11.2 & 9.4 & 8.4 & 7.6 & 6.9 & 6.5 \\
\hline
\end{tabular}

Table 1. Rainfall process of $13 \mathrm{RI}$ schemes
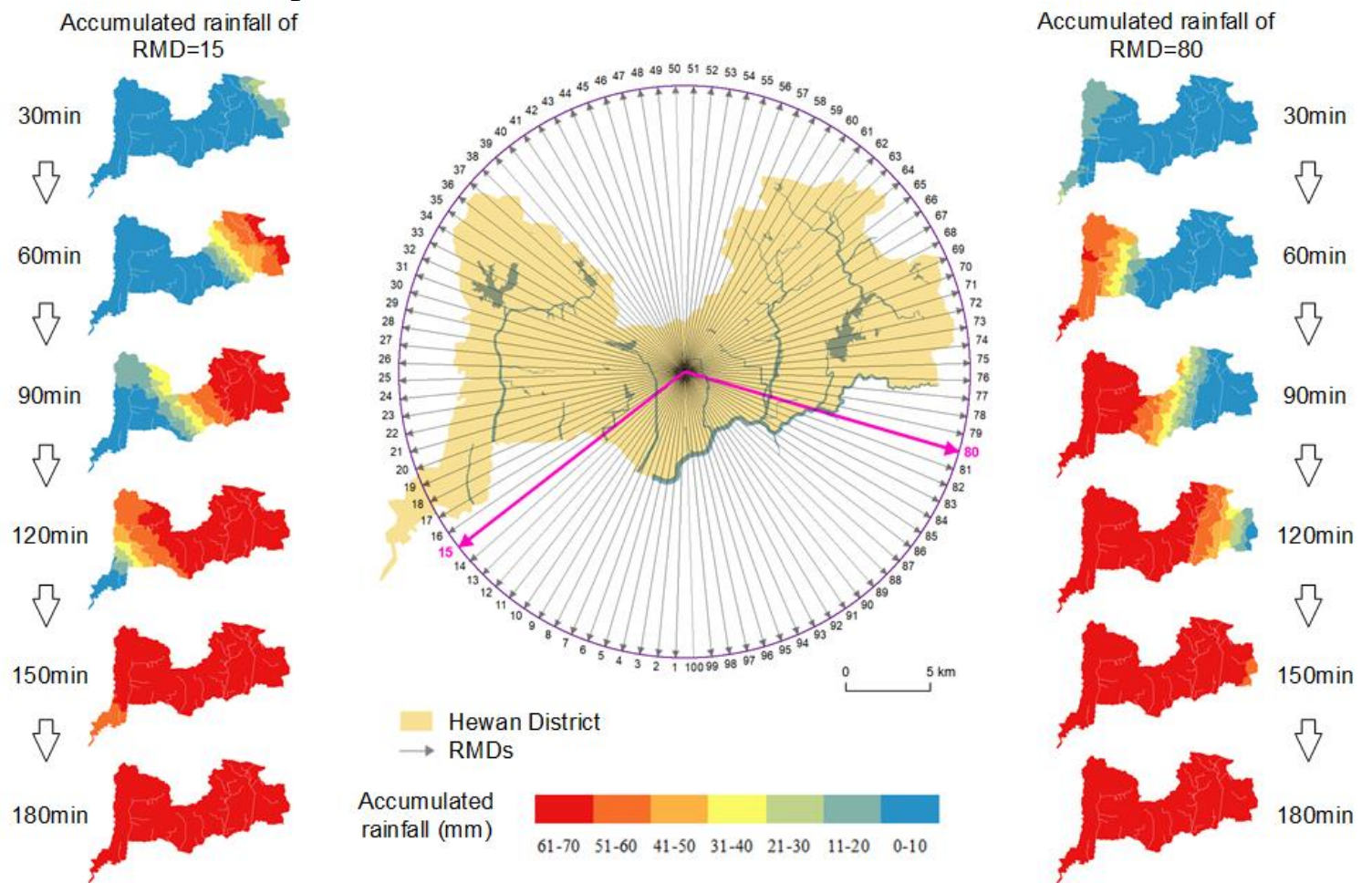

Figure 2. Schematic diagram of rainfall schemes. 
Runoff numerical simulation.We applied the IFMS / urban (Integrated Urban Flood Modeling System) platform, an urban flood simulation platform developed by China Institute of Water Resources and Hydropower Research, to simulate the runoff processes of the studied rivers (Fig.1.). Before the simulations, the model was calibrated by the rainfall- runoff relationship measured from 2018 to 2020. Based on 1313 rainfall processes, we constructed a set of input conditions for the model, including the initial water level of each section, the previous rainfall, and the infiltration process; these conditions were kept consistent for comparison. We calculated the runoff processes of 414 sections in each scheme by using a parallel computing program and output the result to structured files in CSV format.

IFMS / urban model is a first set of flood analysis model developed in China, which has been successful applied in Shenzhen, Beijing, Chengdu, Shanghai, Foshan and other cities ${ }^{32,33}$. Its main modules include: (1) Flood simulation and analysis: River, lake, nearshore flow, flood simulation analysis and calculation of flood protection area and flood storage area; urban rainstorm and waterlogging, overflow (break) flood and dam break flood simulation Analysis; storm surge simulation and analysis; (2) Engineering scheduling simulation: reservoir and lake gate dam, weir, culvert, box culvert and pumping station and other water conservancy engineering facilities scheduling simulation; pipeline one-way valve control; lake reservoir, underground storage tank storage and so on. (3) Data management and pre-processing functions: 2D and 3D data and result display platform; data pre-processing (grid generation, pipeline processing, data management).

Index of peak runoff deviation. We designed a concise index to describe the peak runoff deviation (equation 1):

$$
I_{f p}=\frac{Q_{f p}}{Q_{p}}
$$

where $I_{f p}$ is the peak runoff deviation of a section caused by the rainfall scheme with $\mathrm{RI}=p$ and $\mathrm{RMD}=f, \mathrm{Q}_{\mathrm{p}}$ is the peak runoff $\left(\mathrm{m}^{3} / \mathrm{s}\right)$ of the section under the condition of a synchronous rainfall scheme with $\mathrm{RI}=p$, and $Q_{f p}$ is the peak runoff $\left(\mathrm{m}^{3} / \mathrm{s}\right)$ with $\mathrm{RI}=p$ and $\mathrm{RMD}=f$, where $\mathrm{f} \in 1$, $2 \ldots, 100$.

In this paper, the $I_{f p}$ values of 414 sections were extracted from all 1300 rainfall processes.

RMD and flow concentration direction. The trend in a set of line features is measured by calculating the average angle of the lines, which called the "Linear Directional Mean"(LDM) in GIS $^{34,35}$. The LDM often represents the paths of objects that move, such as rainfall. We use the LDM to represent the confluence direction above a certain river section (equation 2):

$$
\mathrm{LDM}=\arctan \frac{\sum_{i=1}^{n} \sin \theta_{i}}{\sum_{i=1}^{n} \cos \theta_{i}}
$$

where $\theta_{i}$ is the angle between section $\mathrm{i}-1$ and section $\mathrm{i}$ in the confluence area.

The LDM is adjusted according to the angle quadrant, and the adjusted LDM is between $0^{\circ}$ and $360^{\circ}$ : 


$$
\mathrm{LDM}= \begin{cases}L D M, & \sum_{i=1}^{n} \sin \theta_{i} \geq 0 \text { and } \\ 180-L D M, & \sum_{i=1}^{n} \cos \theta_{i}>0 \\ 360-L D M, & \sum_{i=1}^{n} \sin \theta_{i} \geq 0 \text { and } \sum_{i=1}^{n} \cos \theta_{i}<0 \\ 180+L D M, & \sum_{i=1}^{n} \sin \theta_{i}<0 \text { and } \sum_{i=1}^{n} \cos \theta_{i}>0\end{cases}
$$

The angle between the LDM and RMD is calculated as equation 3:

$$
\Delta_{L D M}= \begin{cases}\left|D_{\text {rainfall }}-L D M_{\text {river }}\right|, & \left|D_{\text {rainfall }}-L D M_{\text {river }}\right| \leq 180 \\ 360-\left|D_{\text {rainfall }}-L D M_{\text {river }}\right|, & \left|D_{\text {rainfall }}-L D M_{\text {river }}\right|>180\end{cases}
$$

where $D_{\text {rainfall }}$ represents RMD, $L D M_{\text {river }}$ represents the LDM, and $\Delta_{L D M}$ is between 0 and $180^{\circ}$.

Dynamic clustering of sections. We use the dynamic clustering machine learning method to classify the $I_{f p}$ values of all sections. The $I_{f p}$ value of each section in different RMD with same $\mathrm{RI}$ is used as the attribute to construct the sample set. The calculation is as follows:

$$
\begin{gathered}
S_{i}=\left\{I_{f(1) p}, I_{f(2) p}, \ldots I_{f(100) p}\right\} \\
\Omega=\left\{S_{1}, S_{2}, \ldots S_{429}\right\}
\end{gathered}
$$

where $S_{i}$ is section i and $I_{f(1) p}$ is the simulated result with $\mathrm{RMD}=f(1)$ and $\mathrm{RI}=p$.

The dynamic cluster analysis method is used to classify the sections in $\Omega$; then, the features of each subset, that is, the typical features influencing the peak runoff of the section, are extracted.

The k-means clustering algorithm is used to classify low dimensional with 4 steps:

(1) A total of $\mathrm{r}$ initial cluster centers are set up: $Z_{1}(p), Z_{2}(p), \ldots \ldots Z_{r}(p)$, where $\mathrm{p}$ is the number of iterations.

(2) The distance from samples $\mathrm{x}(x \in X)$ to each cluster center is calculated,

$$
\text { if } D_{x}(j)=\min \left\{D_{x}(i)\right\} \quad i=1,2, \cdots \mathrm{r} \text {, then } x \in S_{j}
$$

where $S_{j}$ represents cluster j with the center of $Z_{j}$.

(3) The new center of each cluster is calculated. The new center of $Z_{j}$ is calculated as follows.

$$
Z_{j}(p+1)=\frac{1}{N} \sum_{i=1}^{N} x_{i} \quad, j=1,2, \cdots r
$$

where $\mathrm{N}$ is the number of samples contained in cluster $S_{j}$ and $x_{i}$ is sample i. Using $Z_{j}(p+1)$ as the new cluster center, the clustering criterion function can be minimized:

$$
J_{j}=\left[\sum_{x \in S_{j}(k)}\left\|x-z_{j}(k+1)\right\|^{2}\right]^{\frac{1}{2}}
$$

where $j=1,2, \cdots, K$.

(4) If $Z_{j}(p+1) \neq Z_{j}(p), j=1,2, \ldots .$. r, then go to $\operatorname{step}(2)$; if $Z_{j}(p+1)=Z_{j}(p), \mathrm{j}=1,2, \ldots \ldots$.r, then cease the iteration. 
In this paper, different $r$ values are calculated, and the initial values of different cluster centers are selected for the k-means cluster analysis. Then, the rainstorms are divided into 3 modes. The mean value of each rainstorm is taken as a typical rainstorm mode.

In addition, we reconstruct the typical features of the river sections. With the inverse calculation of the principal component analysis, the low-dimensional array is reduced to a highdimensional array to express the spatiotemporal process of each rainstorm. The i clustering centers are reconstructed into $i \times m$ matrices (equation 6 ):

$$
X_{a p p}=Z_{i \times p} \times \mathrm{V}_{m \times p}{ }^{\prime}
$$

Where $\mathrm{i}$ is the number of rainstorm modes and $\mathrm{m}$ is the dimension of the original data.

\section{Results and Discussion}

influence of variation in RI and RMD combinations on the peak runoff. We found that the influence of variation in RI and RMD combinations on the peak runoff can reach $30 \%$ based on the index of peak runoff deviation $\left(I_{f p}\right)$ in the study area. The statistics of $538200 I_{f p} \mathrm{~S}$ show that the variations in the RI and RMD are more likely to cause negative effects on peak runoff, with $77.1 \%$ of $I_{f p} \mathrm{~s}<1.0$ and $22.9 \%$ of $I_{f p} \mathrm{~S}>1.0$. However, this influence is always ignored, possibly due to most $I_{f p} \mathrm{~S}(83.3 \%)$ ranging from 0.9 to 1.1 , indicating that the effect of these variations is smaller than $10 \%$ in most instances. Additionally, a heavy RI will reduce the effect of RMD on the peak runoff, with more concentrated of $I_{f p}$ S value of approximately 1.0 correspondingly with the more enhanced RI. We found that $96 \%$ of $I_{f p} \mathrm{~S}$ values ranged from 0.9 to 1.1 when RI $>70 \mathrm{~mm} / \mathrm{h}$. Furthermore, the range of $I_{f p} \mathrm{~s}$ decreased to $0.95-1.05$ when the RI reach an extreme value larger than the once-in-one-hundred-years value $(100 \mathrm{~mm} / \mathrm{h})$. We also found that the duration of the peak runoff was lengthened with extremely high RI values (Fig.3), which is associated with the processes of drainage networks operating under maximum waterloggingelimination capacities. Fig.3(A) shows that the heavier the RI is, the more concentrated the $I_{f p}$ is between 0.9 and 1.1, and the number of $I_{f p}$ values less than 1.0 is obviously greater than that of $I_{f p}$ values more than 1 for all RIs.Fig.3(B) shows that with an increase in the RI, the fluctuation range of $I_{f p}$ decreases obviously and tends toward 1.0.

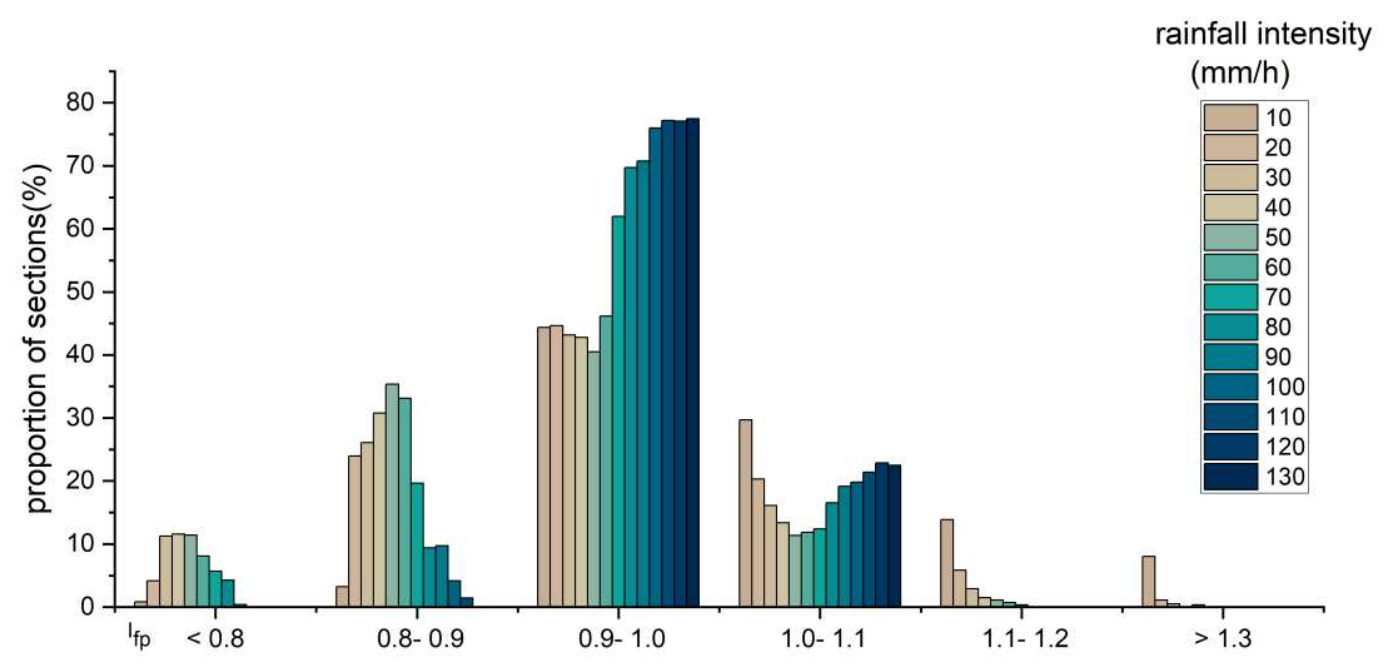




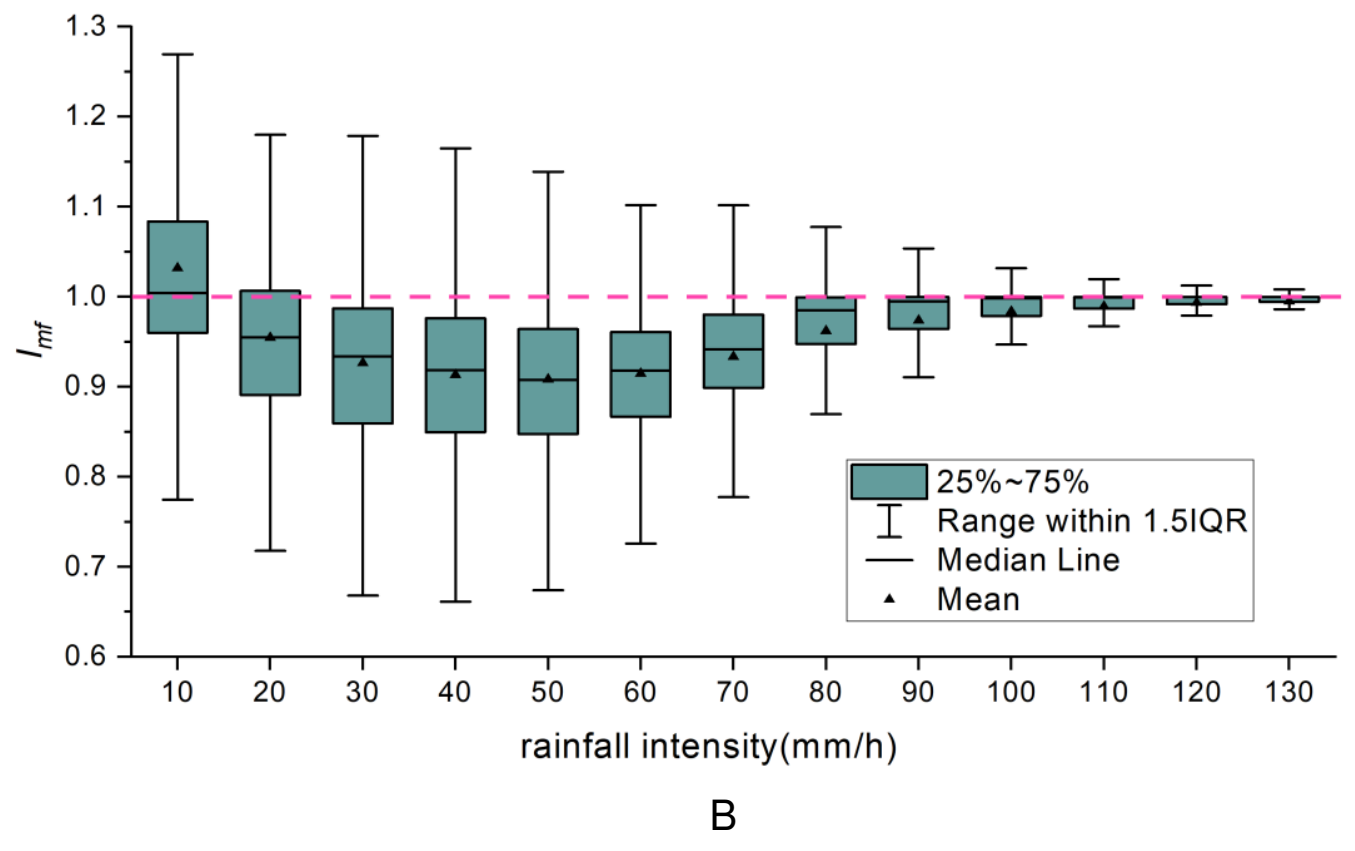

Figure 3. Influence of the RI and RMD on the peak runoff. (A) The distribution of $I_{f p}$ values under 13 different RIs. $(B)$ The distribution of $I_{f p}$ under different RIs.

influence of variation in RMD on the peak runoff. To estimate the impact of RMD, we isolate the effect of RMD from the RI by analyzing the spatial pattern of the RMD impact under similar RI. Based on the dynamic clustering of 414 sections with 100 RMDs each, we do find three typical patterns with proportions of $42 \%, 21 \%$ and $37 \%$ of total number of sections, including 1) model 1 shows a nondirectional effect of RMD by reducing the peak runoff with most $\mathrm{I}_{\mathrm{fp}} \mathrm{S}<1.0 ; 2$ ) model 2 shows an obvious directional effect of RMD with a symmetrical distribution of $\mathrm{I}_{\mathrm{fp}} \mathrm{s}$, in which the minimum effect of direction is opposite to direction of the maximum; 3 ) model 3 shows completely no obvious effect of RMD on peak runoff neither in direction nor in magnitude with $\mathrm{I}_{\mathrm{fp}} \mathrm{S}$ approximately equal to 1.0(Fig.4).

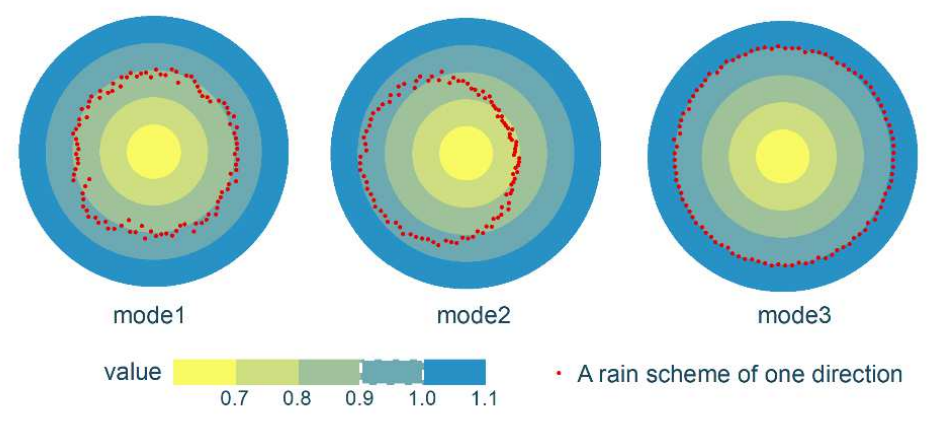

Figure 4. Distribution of $I_{f p}$ s for typical modes

Spatially, these three models are primarily related to the location of sections in rivers(Fig.5). 


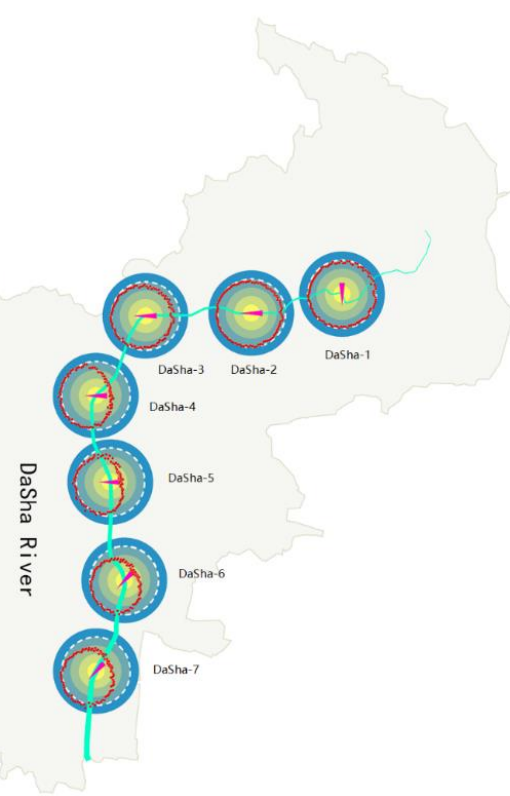

A

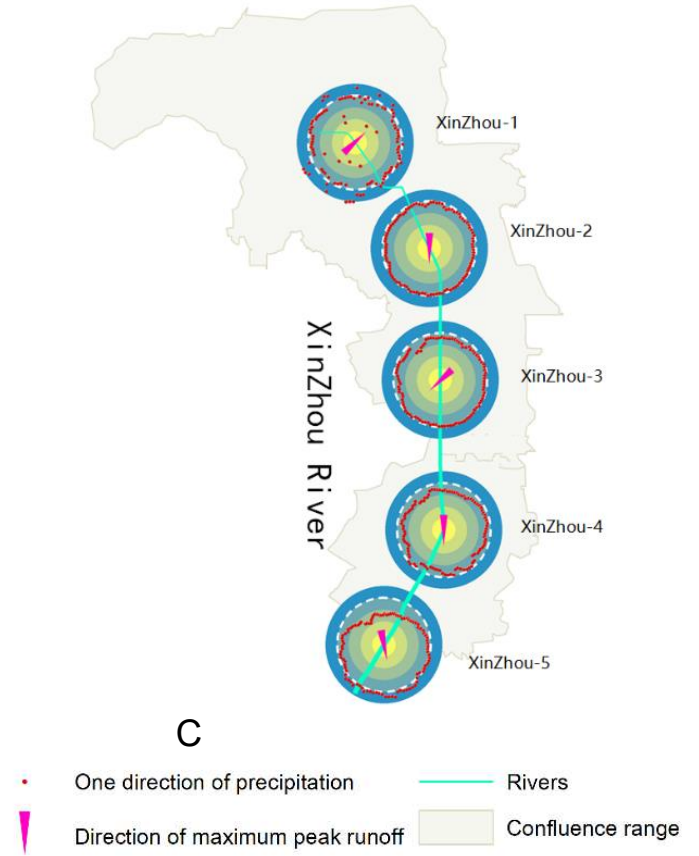

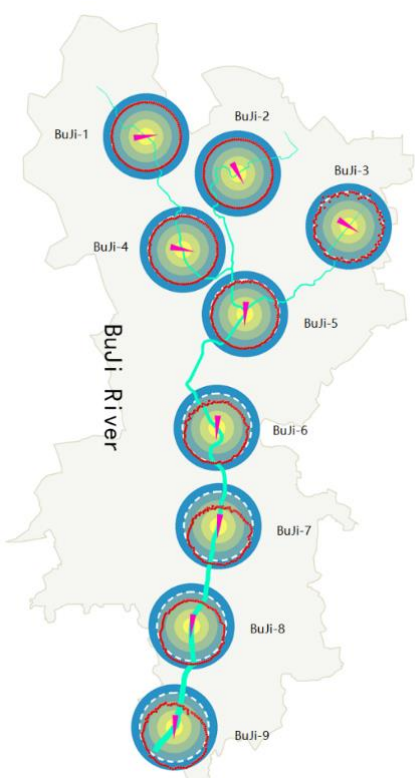

B

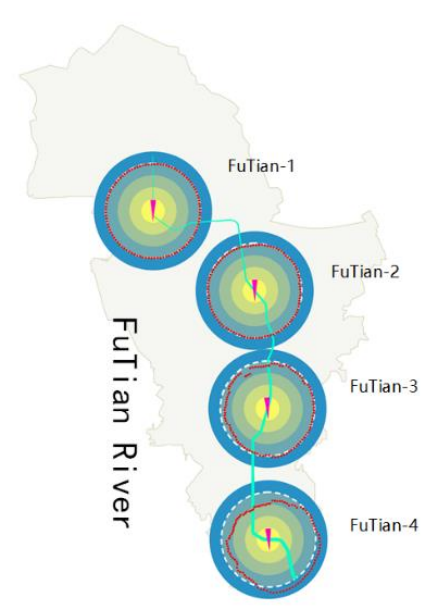

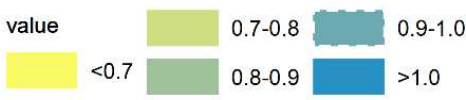

Figure 5. Influence of the peak runoff on the sections of four rivers. (A) Dasha River. (B) Buji River. (C) Xinzhou River. (D) Futian River. Only certain parts of the 414 sections are drawn.

Fig. 5 shows that the in lower reaches of the rivers, the larger the variation range of $I_{f p}$ is, the more symmetrical the influence is.In model 1 and model 3, the influence of RMD on the peak runoff is negligible in the upper reaches of the river. However, model 2 shows symmetrical variations in the lower reaches of the river. We also find that the river length potentially influences the RMD effect. Taking 4 rivers in Shenzhen as an example, the Dasha River and Buji River show the effect of model 2 from middle reaches to lower reaches. While, this effect occurs at the ends of the lower reaches in the other two rivers, Xinzhou River and Futian River, the 
lengths of which are just half of the two aforementioned rivers. The impact of RMD on the peak runoff is primarily present in the lower reaches, possibly due to the longer duration and larger area of the flow concentration that gradually increasing the asynchrony of rainfall with the peak runoff. Furthermore, we find a slightly jagged shape in models of $\mathrm{I}_{\mathrm{fp}} \mathrm{S}$ compared with natural watershed, which may be explained by the uneven distribution of underground pipes used to drain flows into rivers in urban areas and their corresponding covering areas. In rapidly urbanizing area, the lack of pipe network datasets will increase the complexity of urban flood analyses.

How RMD affect the peak runoff ? To further understand how RMD affect the peak runoff, we calculated three angles of sections: $\theta_{\max }$ PR-FC (the angle between RMD with maximum peak runoff and flow concentration direction), $\theta_{\text {min PR-FC (the angle between RMD with minimum peak }}$ runoff and flow concentration direction) and $\theta_{\max } \mathrm{PR}-\mathrm{FD}$ (the angle between RMD with maximum peak runoff and flow direction). In this paper, we used "Linear Directional Mean"(LDM) to represent the flow concentration direction, which is the geometric mean of all the reaches upstream the section in this paper. In contrast with the flow direction, we do find a significant relationship between RMD and the flow concentration direction during maximum peak runoff (Fig.6), with decreasing trends of $\theta_{\max }$ PR-FC from upstream to downstream. For example, the angles of the second half of downstream reaches of the Buji River are almost smaller than $20^{\circ}$, and some

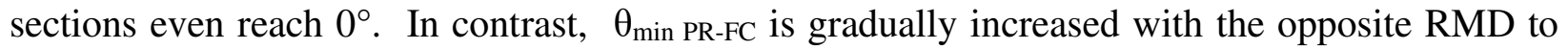
$\theta_{\max }$ PR-FC, which is consistent with the result of model 2 shown in Fig.4. Additionally, the $\theta_{\max }$ PRFC values are larger in more meandering rivers (e.g., Dasha River) than in rivers with straight channels(e.g., Buji River). We can therefore conclude that RMD is a significant factor to peak runoff downstream in urban areas, and this influence is not isolated but needs to be combined with the spatial feature of rivers such as direction and bending. 

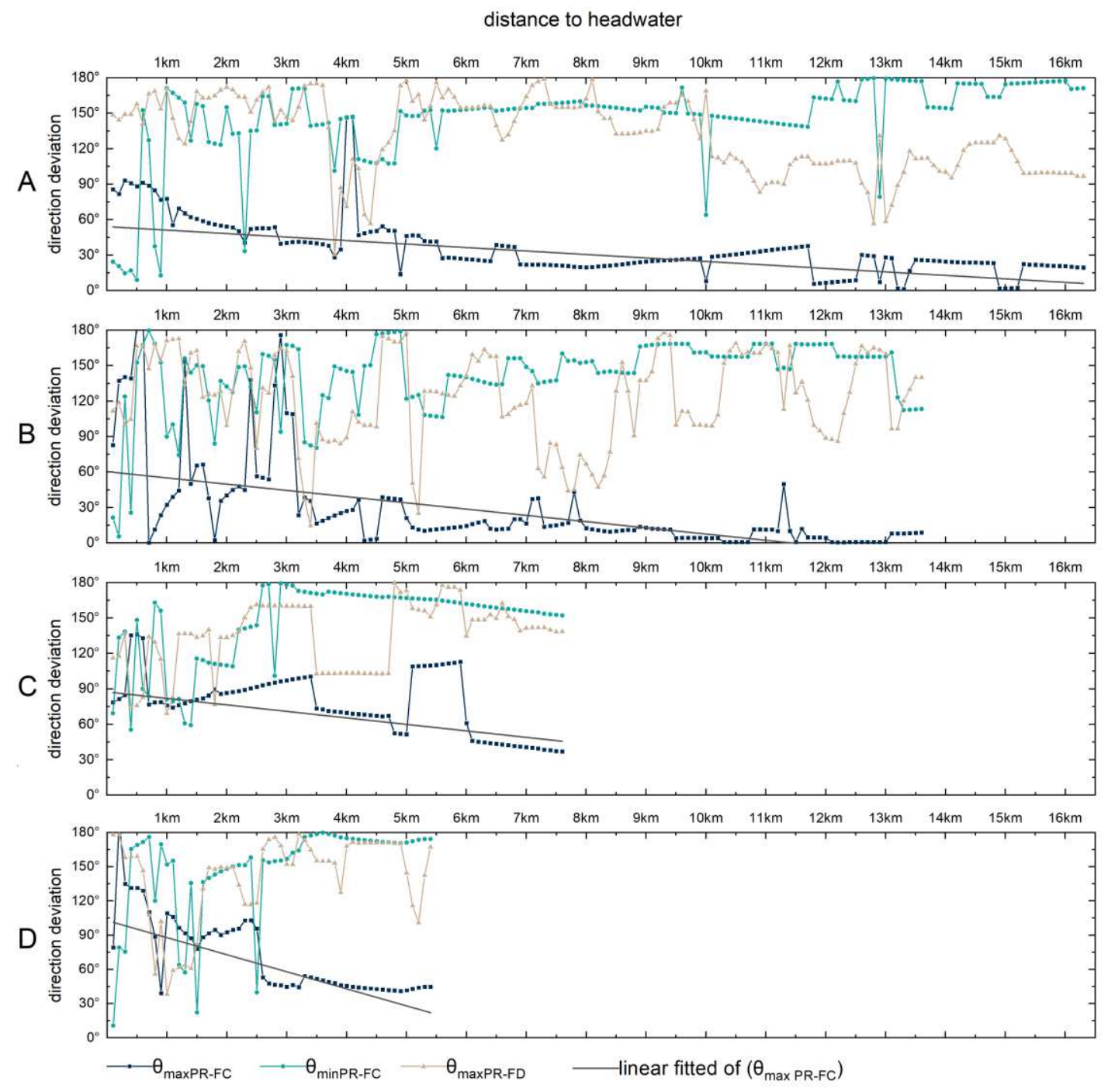

Figure 6. Influences of RMD and the direction of river confluence on the peak runoff. (A) Dasha River. (B) Buji River. (C) Xinzhou River. (D) Futian River.

The impact of RMD on the peak runoff indicates that river flood risks and discharge capacities should be evaluated from more rainfall variations including RI, rainfall duration, etc. Commonly used method that do not consider the impact of RMD, such as constructing rainfall processes by independent zoning ${ }^{32,36,37}$, may underestimate or overestimate the peak runoff magnitude in rivers. Figure 7 compares the difference of peak runoff between considering and not considering the impact of RMD, in 4 urban rivers of Shenzhen with similar RIs. We found that the uncertainties yielded from RMD may reach $-40 \%$ and $50 \%$ (Fig.7). In most cases, these uncertainties range from $-20 \%$ to $20 \%$. These analyses confirm that the impact of RMD on runoff cannot be ignored in urban hydrologic management. 


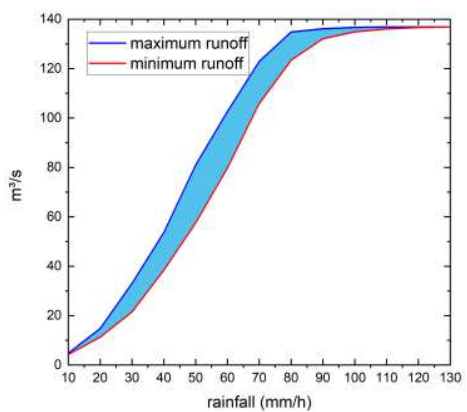

A

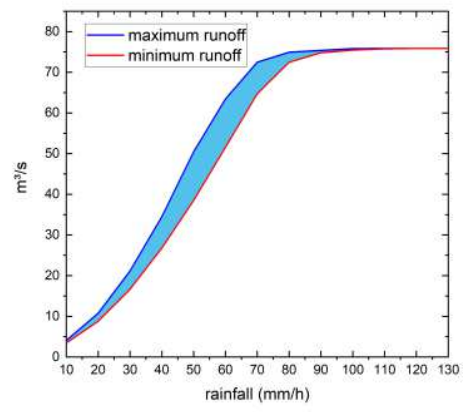

$\mathrm{D}$

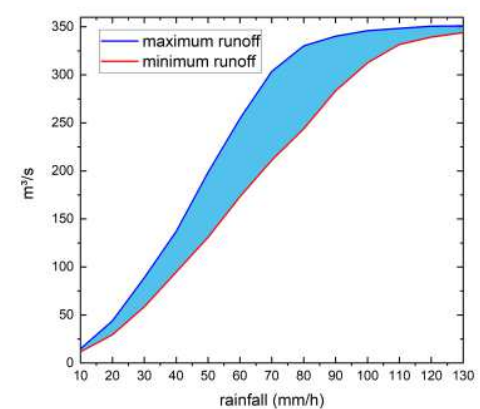

B

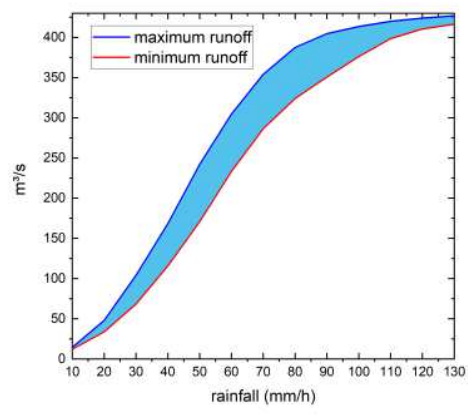

$\mathrm{E}$

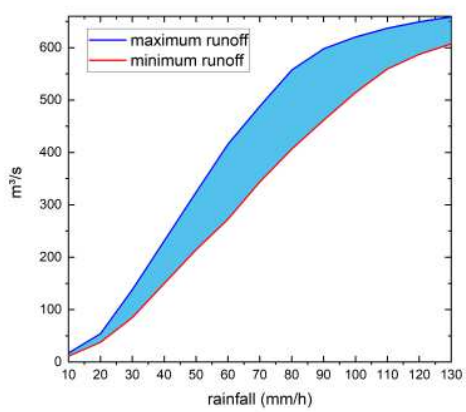

$\mathrm{C}$

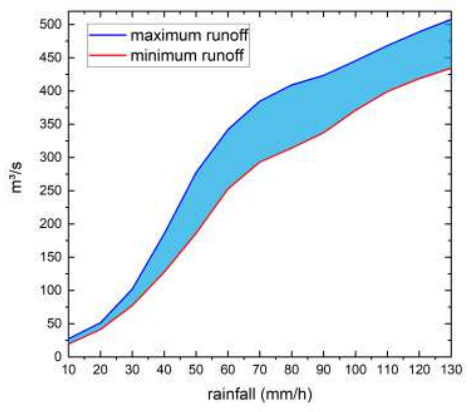

$\mathrm{F}$

Figure 7. The peak runoff ranges with the same RI value but different RMDs for 6 river sections. A, Section 50 of the Dasha River. B, Section 100 of the Dasha River. C, Section 150 of the Dasha River. D, Section 30 of the Buji River. E, Section 80 of the Buji River. F, Section 130 of the Buji River.

\section{Conclusions}

Our results show that RMDs are very likely responsible for variations in flood risks in different sections of urban rivers, which should not be ignored in urban hydrologic management. Although the impact of RMD on peak runoff in rivers is always covered up by heavy RI, this impact is significant in the downstream reaches of urban river when combined with spatial features of rivers, such as the river direction and bending. We propose that RMD should be involved in urban hydrologic models and predication, as it may yield substantial uncertainties in peak runoff in rivers. We provide an empirical evaluation to quantify the contribution of RMD to peak runoff in urban rivers, indicating that the river flood risk and discharge capacity should be evaluated based on more variations of rainfall such as RMD. Given the importance of the prevention and treatment of urban waterlogging with the accelerating process of urbanization, this empirical evaluation of peak runoff variations due to changing RMDs provides critical information to inform policy and decision making.

\section{References}

1 Lai, Y. et al. Greater flood risks in response to slowdown of tropical cyclones over the coast of China. Proceedings of the National Academy of Sciences 117, 14751-14755, doi:10.1073/pnas.1918987117 (2020).

2 Degaetano, A. Time-Dependent Changes in Extreme-Precipitation Return-Period Amounts in the Continental United States. Journal of Applied Meteorology and Climatology 48, doi:10.1175/2009JAMC2179.1 (2009).

3 Papalexiou, S. M. \& Montanari, A. Global and Regional Increase of Precipitation Extremes under Global Warming. Water Resources Research, doi:10.1029/2018WR024067 (2019). 

134, 387-401 (2016).

5 Cristiano, E., Deidda, R. \& Viola, F. EHSMu: a New Ecohydrological Streamflow Model to Estimate Runoff in Urban Areas. Water Resources Management 34, doi:10.1007/s11269-020-02696-0 (2020). Davenport, F., Burke, M. \& Diffenbaugh, N. Contribution of historical precipitation change to US flood damages. Proceedings of the National Academy of Sciences 118, e2017524118, doi:10.1073/pnas.2017524118 (2021). Xu, Z., Chen, H, Ren, M \& Cheng, T. Progress on disaster mechanism and risk assessment of urban flood/waterlogging disasters in China. Shuikexue Jinzhan/Advances in Water Science 31, 713-724, doi:10.14042/j.cnki.32.1309.2020.05.008 (2020). ten et al. The role of storm scale, position and movement in controlling urban flood response. Hydrology \& Earth System Sciences (2018).

Yan, M., Chan, J. \& Zhao, K. Impacts of Urbanization on the Precipitation Characteristics in Guangdong Province, China. Advances in Atmospheric Sciences (2020). Marelle, L. et al. Urbanization in megacities increases the frequency of extreme precipitation events far more than their intensity. Environmental Research Letters, doi:10.1088/1748-9326/abcc8f (2020).

11 Cristiano, E., ten Veldhuis, M. C. \& van de Giesen, N. Spatial and temporal variability of rainfall and their effects on hydrological response in urban areas - a review. Hydrol. Earth Syst. Sci. 21, 3859-3878, doi:10.5194/hess-21-38592017 (2017).

12 Hailegeorgis, T. T. \& Alfredsen, K. Analyses of extreme precipitation and runoff events including uncertainties and reliability in design and management of urban water infrastructure. Journal of Hydrology 544, 290-305, doi:https://doi.org/10.1016/j.jhydrol.2016.11.037 (2017).

13 Hénonin, J. et al. Urban flood real-time forecasting and modelling: a state-of-the-art review. (2010).

$14 \mathrm{Xu}, \mathrm{H}$., Ma, C., Xu, K., Lian, J. \& Long, Y. Staged optimization of urban drainage systems considering climate change and hydrological model uncertainty. Journal of Hydrology, 124959 (2020). Pang, B., Shi, S., Zhao, G., Shi, R. \& Zhu, Z. Uncertainty Assessment of Urban Hydrological Modelling from a Multiple Objective Perspective. Water 12, 1393 (2020).

Cristiano, E., Ten Veldhuis, M.-C., Wright, D., Smith, J. \& van de Giesen, N. The Influence of Rainfall and Catchment Critical Scales on Urban Hydrological Response Sensitivity. Water Resources Research 55, doi:10.1029/2018WR024143 (2019).

Rossman, L. Modeling Low Impact Deve (2010).

Lyu, H., Ni, G., Cao, X., Ma, Y. \& Tian, F. Effect of Temporal Resolution of Rainfall on Simulation of Urban Flood Processes. Water 10, 880, doi:10.3390/w10070880 (2018).

condition in Kolkata Metropolitan Area. Urban Climate 32, doi:10.1016/j.uclim.2020.100599 (2020). $\mathrm{Mu}$, D. et al. Impact of temporal rainfall patterns on flash floods in Hue City, Vietnam. Journal of Flood Risk Management 14, e12668, doi:10.1111/jfr3.12668 (2020). Zoccatelli, D., Borga, M., Viglione, A., Chirico, G. B. \& Blöschl, G. Spatial moments of catchment rainfall: rainfall spatial organisation, basin morphology, and flood response. Hydrology and Earth System Sciences 15, doi:10.5194/hess-15-3767-2011 (2011).

Smith, J. A., Bradley, A. A. \& Baeck, M. L. The SpaceTime Structure of Extreme Storm Rainfall in the Southern Plains. Journal of Applied Meteorology 33, 1402-1417 (1994). hydrograph. Hydrological Processes 11, 1649-1669 (1997).

Emmanuel, I., Andrieu, H., Leblois, E. \& Flahaut, B. Temporal and spatial variability of rainfall at the urban hydrological scale. Journal of Hydrology 430-431, 162-172 (2012).

Nikolopoulos, E. I., Borga, M., Zoccatelli, D. \& Anagnostou, E. N. Catchment-scale storm velocity: quantification, scale dependence and effect on flood response. International Association of Scientific Hydrology Bulletin 59, 13631376 (2014). Emmanuel, I., Andrieu, H., Leblois, E., Janey, N. \& Payrastre, O. Influence of rainfall spatial variability on rainfallrunoff modelling: Benefit of a simulation approach? Journal of Hydrology 531, doi:10.1016/j.jhydrol.2015.04.058 (2015).

Spyrou, N. I. et al. Catchment-Scale Storm Velocity: Quantification, Scale Dependence and Effect on Flood Response. (2020).

9 Liu, Y. Y., Li, L., Liu, Y. S., Chan, P. W. \& Zhang, W. H. Dynamic spatial-temporal precipitation distribution models for short-duration rainstorms in Shenzhen, China based on machine learning. Atmospheric Research 237, 104861 (2020).

30 Hallegatte, S., Green, C., Nicholls, R. \& Corfee-Morlot, J. Future flood losses in major coastal cities. Nature Climate Change 3, 802-806, doi:10.1038/nclimate1979 (2013). 
Zhou, L., Wu, X., Ji, Z. \& Gao, G. Characteristic analysis of rainstorm-induced catastrophe and the countermeasures of flood hazard mitigation about Shenzhen city. Geomatics (2017).

32 Zang, W. et al. Impact of urbanization on hydrological processes under different precipitation scenarios. Natural Hazards: Journal of the International Society for the Prevention and Mitigation of Natural Hazards 99 (2019).

33 Haijun, Y. U. \& Jianming, M. A. Application of IFMS Urban software in urban flood risk mapping. China Flood \& Drought Management (2018).

34 Feng et al. A simplified linear feature matching method using decision tree analysis, weighted linear directional mean, and topological relationships. International Journal of Geographical Information Science (2017). Mitchell, A. The ESRI Guide to GIS Analysis. (1999).

36 Wheater, H. S. et al. Spatial-temporal rainfall modelling for flood risk estimation. Stochastic Environmental Research \& Risk Assessment 19, 403-416 (2005).

37 Aronica, G. \& Cannarozzo, M. Studying the hydrological response of urban catchments using a semi-distributed linear non-linear model. Journal of Hydrology 238, 35-43 (2000).

\section{Acknowledgments}

This work was supported by National Natural Science Foundation of China (Grant NO. 41822104), the Strategic Priority Research Program of the Chinese Academy of Sciences (XDA19040402), the National Key Research and Development Program of China (Grant No. 2017YFB0503005), National Science and Technology Major Project of China's High Resolution Earth Observation system (21-Y20B01-9001-19/22).

\section{Author Contributions}

Yesen Liu collected and processed the data, Yaohuan Huang and Yuanyuan Liu proposed the model and analyzed the results, Yaohuan Huang and Yesen Liu wrote the manuscript.

\section{Conflicts of Interest}

The authors declare no conflict of interest. 